Virtual Mentor. October 2003, Volume 5, Number 10.

doi: 10.1001/virtualmentor.2003.5.10.ccas3-0310

Clinical Cases

\title{
Confidentiality of Patient Records Requested by the Court
}

\section{Psychiatrists can take various steps to uphold patient confidentiality when faced with a court order to disclose a patient's medical records.}

\author{
Commentary by Howard Zonana, MD, and Jeffrey L. Metzner
}

Dr. Santos has been seeing Kyle Green for depression for 8 months. When they began working together, Mr. Green, an accountant, said that his 13-year marriage was falling apart. His work situation was even worse, he said. He worried that his employer, a well-known accounting firm, might be engaging in practices that would considered unethical if scrutinized closely. He was boxed in, he said. He couldn't jeopardize his income and look for another job at this time. Nor could he focus on attempting to fix his marriage due to worry and long hours at the job.

Kyle Green had begun staying late at the office, documenting all his work, who had requested it, and what exactly he had done in response. He'd arrive home at $8 \mathrm{PM}$. He and his wife would eat at the same table, discussing only household finances and other matters that had to be decided mutually, and share a bottle of wine. Kyle said his wife would get increasingly nasty in her words and attitude, so he would leave the table, look at the newspaper for half an hour, and go to bed by 10 or 10:30.

He wasn't seeing much of his 2 daughters. On weekends, his wife would hustle the girls, aged 8 and 11, out of the house. She said she did not want them exposed to the bickering and hostility between their parents. Besides, she said, Kyle was so preoccupied that he wasn't any company for the girls and couldn't give them the attention they needed. Sometimes the 3 of them wouldn't return until late evening, Kyle said, and his wife would only say they had been at friends. Kyle didn't want to interrogate the girls, but, in answer to his general query about what they had done while out of the house, they usually said that their mother had dropped them off at friends' houses and picked them up later.

Immediately before coming to see Dr. Santos for the first time, Kyle Green had made the mistake—as he now saw it— of telling his wife he didn't think he could carry on with the marriage or at work. "I ought to just check out," he said in a particularly low and slightly boozy moment. "That would solve everything." Mrs. Green had insisted that her husband get help, and Kyle had started therapy with Dr. Santos. Dr. Santos had tried Kyle on a couple of antidepressant medications. He hadn't been responsive yet, and she was searching for a third. They were focusing on his work problems and the marriage situation.

Mrs. Green sued for divorce and custody of the 2 girls. Moreover, she did not want her husband to have visitation rights. She said he had a drinking problem and was suicidal. Her attorney wrote to Dr. Santos subpoenaing Kyle Green's records. When Dr. Santos informed Kyle, he objected to the records being released. He had been more despondent than ever since the divorce proceedings had begun and had spoken candidly with Dr. Santos about suicide.

In fact, at first news of the suit, he had stated more emphatically than previously that he had nothing else to lose and didn't see any reason to continue the painful daily routine. In addition to these admissions, Kyle had been discussing his job with Dr. Santos, trying to decide what he should do with that uncomfortable and possibly unethical situation. He certainly did not want this information to get into other hands. 
Kyle would not accuse his wife of any unsuitable behavior, so Dr. Santos couldn't get a good idea of why the marriage was failing. Kyle said he didn't know why his wife had stopped loving him and become so nasty to him, but he assumed the responsibility for the failure of the marriage. "Why should she love me?" he asked Dr. Santos.

\section{Commentary 1}

by Howard Zonana, MD

Divorce and custody battles can be extremely bitter and divisive for patients, as well as providing landmines for their treatment providers. This case raises at least 2 major areas for discussion; (1) how to deal with subpoenas and (2) how to think about potential role conflicts in the context of a divorce and custody dispute.

\section{Subpoenas: what to do}

The first principle is that subpoenas should not be ignored. To do so could have negative consequences for both the patient and the psychiatrist. The most prudent course would be to make sure that the patient has legal representation and then have him sign a release that allows you to notify his attorney of the demand for disclosure of treatment records. This gives the attorney the opportunity to raise objections to the court regarding both the need for the records and the extent and timing of any disclosures.

Analyzing psychiatric privilege in custody disputes is complex and varies considerably among states. Privileges may interfere with the goal of obtaining the best evidence by protecting certain pertinent information from the court's consideration. The protection of children has been deemed a compelling state interest that justifies the overriding of the privilege, eg, in situations involving known or suspected child abuse or neglect.

Many state courts will permit some access to psychiatric records if they are considered relevant. The "relevance" analysis may be interpreted broadly, including any factors that appear to be necessary. In theory, this aids the court's fact-finding. In reality, custody disputes in the adversarial system frequently result in each party's making an issue of every aspect of the other's life, hoping to impress the court by showing what a bad parent the other is. Any past history of mental health treatment becomes evidence of the lack of fitness to have custody of the child.

The general rule for waiver of psychiatrist-patient privilege is that the patient must put his or her mental health at issue and the court must find that "it is more important to the interests of justice that communications be disclosed than that the relationship between the person and the psychiatrist be protected." The burden of persuading the court that justice requires the testimony's admission is on the party seeking to admit testimony. These general rules for waiver are difficult to apply in the child custody setting.

First, there is no unanimity regarding the question of whether merely seeking custody puts a parent's mental health at issue and waives the privilege. Second, some courts believe that a balancing of interests is required; privilege is overridden if the evidentiary need for disclosure of the contents of a patient's treatment sessions outweighs the patient's privacy interests. Psychiatrists prefer the view in the US Supreme Court ruling in Jaffee v Redmond that created a patient-psychiatrist privilege in federal courts:

"If the purpose of the privilege is to be served, the participants in the confidential conversation [patient and physician] must be able to predict with some degree of certainty whether particular discussions will be protected" [1].

Thus the outcome is not clear in the case of Dr. Santos even though the information may, at first glance, seem relevant. In re Matthew $R$. shows how a Maryland appellate court overruled the trial court's order of disclosure of all records pertaining to the mother's treatment for bipolar disorder, noting that "if one parent in a custody dispute could, by challenging the other parent's mental fitness, get access to the other parent's records by his or her response to the allegations, the privilege would be meaningless" [2]. The court reasoned that "the benefits to society of having confidential and privileged treatment available to troubled parents far outweighs the limitations placed upon the court by not having such information revealed." 


\section{Roles: adversaries and parents}

The adversary system can be highly distressing to all participants in custody disputes. Although attempts have been made to create a more humane and child-protective courtroom, engaging in a battle with family members is not a positive experience; certainly it is not for the children who are often placed in the middle of this internecine warfare. Nor is it generally friendly to the parents. The adversary system requires parties to refrain from addressing each other directly; they may communicate only through their attorneys. The adversary system forces parties to present information in a way to help them "win" their case, rather than to examine the facts contextually. For this reason, many states require some efforts at mediation before a full-blown trial [3].

It is not uncommon in this context for attorneys to request letters from treating psychiatrists attesting to the patient's ability to parent. Such attempts add the role of expert witness to the treatment role. Ethical guidelines developed by the American Academy of Psychiatry and the Law for psychiatrists in this situation recommend that treating psychiatrists should avoid/decline the role of expert. This is recommended for several reasons. First, it may disrupt the treatment relationship, especially if the patient does not succeed in his wishes and blames the psychiatrist-expert for his poor performance. Second, the kind of evaluation required to be an expert witness is very different than an evaluation conducted for therapeutic reasons. The former generally requires interviews with independent sources to confirm information, and a review of all previous records, as well as obtaining psychological testing to bolster clinical impressions. If one is going to offer an opinion that the patient is deserving of custody, an examination of the other spouse would also be required.

If it appears that an expert will be required, it is recommended that a separate expert be hired to evaluate both the children (assessment of special needs) and the parents (capacity to parent and provide for any special needs). In many circumstances the court will appoint an "independent" expert who will report to both sides and the court. This does not preclude the parties from hiring additional experts.

Therefore, in my view, Dr. Santos should first let his patient know that he has received a subpoena. Then he should ask if his patient has obtained an attorney to represent him. If so, he should then have his patient sign a release of information form permitting Dr. Santos to talk with his attorney. Dr. Santos should review with both the patient and his attorney their plans regarding how the subpoena will be handled in court and whether they will try to quash the subpoena. Dr. Santos should also review with the attorney what he is likely to say in response to questions regarding his diagnostic impressions and treatment plan if testimony is required by the court. He should also make clear that if expert conclusory testimony is needed regarding who is best able to provide for the child's needs, a separate evaluation by a non-treating forensic expert should be obtained.

\section{References}

1. Jaffee $v$ Redmond, 518 U.S. 1 (1996).

2. In re Matthew R., 688 A.2d 955, 962 (Md. Ct. Spec. App. 1997).

3. Weinstein J. And Never The Twain Shall Meet: The Best Interests of Children and the Adversary.52 U. MIAMI L. REV. 79 (1997). Google Scholar

Howard Zonana, MD, is Professor in the Department of Psychiatry, Yale University School of Medicine; and Clinical Professor [Adjunct] at Yale University Law School. He is the medical director of the American Academy of Psychiatry and the Law.

\section{Commentary 2}

by Jeffrey L Metzner, MD 
Judicial authority to compel disclosure of information revealed in psychiatric treatment for use in custody disputes has been frequently litigated. Such records are more likely to be admitted as evidence when the court is using the "best interest of the child" standard in resolving the custody dispute.

The applicable AMA ethical principles relevant to the subpoenaing of Mr. Green's records are as follows:

Principle III: A physician shall respect the law and also recognize a responsibility to seek changes in those requirements which are contrary to the best interests of the patient.

Principle IV: A physician shall respect the rights of patients, of colleagues, and of other health professionals, and shall safeguard patient confidences within the constraints of the law [1].

The compelled release of psychiatric records by the treating psychiatrist is very problematic for reasons that underlie the ethical principle of confidentiality. Mandatory release of records can destroy an existing treatment relationship and may also deter others from seeking needed treatment.

A subpoena does not require Dr. Santos to send the records to Ms. Green's attorney, although it does require Dr. Green to produce them at a specified time at a particular setting (e.g., deposition, divorce hearing, etc.). Dr. Santos should request Mr. Green to have his attorney file a motion to quash the subpoena, which, if successful, would make Dr. Santos's dilemma moot.

Assuming that the judge does not quash the subpoena, what options are available to Dr. Santos? An American Psychiatric Association task force has thoughtfully considered this issue. This task force recommended that a court deciding custody should permit the disclosure of confidential information revealed in psychiatric treatment only when the information is likely to be of real importance to the custody determination and is not available from other sources. Such breaches of confidentiality should only occur when substantial evidence before the court indicates that the parent whose treatment records are at issue may be psychologically unfit to function as a parent, and that information revealed in psychiatric treatment will be important in resolving this issue [2].

Mr. Green's attorney could file a motion for an in camera review (i.e., a hearing or discussion with the judge in the privacy of his chambers or when spectators and jurors have been excluded from the courtroom) of Mr. Green's psychiatric records to determine which records, if any, are relevant to the custody proceedings. The court may also appoint an independent psychiatrist to review the record, thus assuring that only information pertinent to the patient's parenting capacity is disclosed. Following such an approach, it is very likely that information concerning Mr. Green's employer's questionable business practices would not be disclosed due to lack of relevancy in the custody dispute. Following the American Psychiatric Association (APA) task force's procedural recommendations, disclosure would be permitted in cases in which it was needed to assure the child's well-being, while confidentiality of the therapeutic relationship would be protected to the maximum extent possible.

Compelled disclosures of certain treatment information occur in other circumstances, such as reporting suspected child abuse and taking steps designed to protect a third party from potential harm by a patient in certain specified circumstances (eg, the so-called Tarasoff exception). Courts, legislators, and health care professionals have struggled to develop a balance between compelling state interests (such as protecting others) and privacy rights of the patient. It is generally recognized that when a person who needs mental health treatment actually obtains mental health treatment, it often protects other persons too-directly or indirectly. Individuals are often less willing to enter treatment if they know that their disclosures to a psychiatrist might later be used against them in some fashion.

The APA encourages psychiatrists to obtain consent before disclosing medical information, even if not legally mandated to do so either by federal (eg, HIPAA) or state law. Doing so invites patients and their psychiatrists to discuss the nature and limits of the psychiatrist's duty to preserve confidentiality. The APA has held, through its Principles of Medical Ethics with Annotations Especially Applicable to Psychiatry, that explicit consent, preferably written, should be obtained from the patient prior to disclosing information to third parties [3]. Thus, Dr. Santos's dilemma could have been significantly lessened had she disclosed to Mr. Green prior to beginning treatment that there were various exceptions to confidentiality, although it would have been unlikely that Dr. Santos could have foreseen 
(and therefore have informed Mr. Green) the specific exception being put forth.

Assuming Dr. Santos follows these recommendations and the court still orders release of Mr. Green's treatment records, Dr. Santos can ethically release these records.

The dilemma being faced by both Mr. Green and Dr. Santos could be minimized by Dr. Santos's style of record keeping. Specifically, it is often possible to maintain adequate treatment records from both a clinical and legal perspective without including potentially embarrassing information in these records. It is easier for the treating psychiatrist to formulate documentation guidelines if he or she assumes that the treatment records will be made available to either the patient or others.

Experience has also demonstrated that, even in the context of compelled disclosures, it is possible to achieve therapeutic benefit by dealing with the information to be disclosed and the disclosure process. For example, Mr. Green's apparent isolation from his children needs to be addressed in therapy. It is more likely a reflection of his depression and the dynamics within his marriage than a matter of poor parenting. His apparent passive stance in the marriage will also need to be addressed, and may become a more focal issue for him as he discusses the possible compelled disclosures. The detrimental effects of compelled disclosures can be minimized if the psychiatrist effectively involves the patient in the disclosure process from both legal and therapeutic perspectives.

\section{References}

1. American Medical Association. Principles of Medical Ethics, American Medical Association, 2001.

2. American Psychiatric Association. Task Force Report 31: Disclosure of psychiatric treatment records in child custody disputes. American Psychiatric Association, Washington, D.C. 1991.

3. HIPAA Educational Packet, 2003. Accessed September 15, 2003 (APA members only).

Jeffrey L. Metzner, MD, is a clinical professor (Adjunct) of psychiatry at the University of Colorado Health Science Center in Denver, Colorado. He is the associate director of the forensic fellowship program at UCHSC. Dr. Metzner is the current chair of the American Psychiatric Association's Council on Psychiatry and Law. He is a former president of the American Academy of Psychiatry and the Law (AAPL).

The people and events in this case are fictional. Resemblance to real events or to names of people, living or dead, is entirely coincidental. The viewpoints expressed on this site are those of the authors and do not necessarily reflect the views and policies of the AMA.

(C) 2003 American Medical Association. All Rights Reserved. 